\title{
OS PROBLEMAS BIOPOLÍTICOS CONTEMPORÂNEOS EM NIKOLAS ROSE
}

\author{
ROSE, Nikolas. \\ The politics of life itself: biomedicine, power, and \\ subjectivity in the twenty-first century. \\ Princeton: Princeton University Press, 2007.
}

\section{POR}

\section{Gabriel de Freitas Gimenes ${ }^{1}$}

\begin{abstract}
Tikolas Rose, professor do Departamento de Sociologia e Coordenador do Centro de Pesquisa para o Estudo de Biociências, Biomedicina, 1 Biotecnologia e Sociedade (BIOS) da London School of Economics and Political Science, tem sido reconhecido pelo trabalho analítico que vem realizando nos últimos vinte anos, o qual gira em torno de uma questão comum: que tipo de seres nós compreendemos que somos, como viemos a nos compreender dessa forma e com quais conseqüências? (ROSE, 2011).
\end{abstract}

Seus primeiros trabalhos buscaram tangenciar tal questão a partir de um estudo sobre os saberes psi, sua disseminação nos discursos e os processos por meio dos quais fomos levados a nos compreender enquanto seres dotados de um profundo espaço interior (psicológico), o qual conteria a verdade sobre nossos desejos, medos, possibilidades, etc. A relação entre essa compreensão psicológica da existência humana, as estratégias de governo, as formas de subjetificação e de controle possíveis foram tratadas em livros tais como The Psychological Complex (1985), Governing the Soul (1989) e Inventing Our Selves (1996).

Recentemente, Rose tem juntado esforços com o antropólogo Paul Rabinow no sentido de divulgar o trabalho de Foucault, estudar sua contribuição ao

${ }^{1}$ Psicólogo pela Universidade Estadual de Londrina, Brasil. gfgimenes@gmail.com 
pensamento crítico e levá-la adiante. Ambos argumentam que a obra de Foucault oferece muitas possibilidades para a análise dos problemas contemporâneos, não apenas pelas ferramentas conceituais que ele desenvolveu, mas também pelo estilo de pensamento e de crítica que ele colocou em prática. No entanto, estes autores apontam a necessidade de um refinamento teórico dos conceitos desenvolvidos por Foucault. Neste sentido, eles afirmam que, apesar da utilização da perspectiva biopolítica em diversas pesquisas, pouca delimitação conceitual sobre o biopoder foi realizada (RABINOW; ROSE, 2003; 2006).

$\mathrm{Na}$ tentativa de um detalhamento conceitual mais preciso, Rabinow e Rose sugerem que o biopoder pode ser compreendido como uma relação entre, no mínimo, três esferas: um conjunto de discursos de verdade sobre os processos vitais dos seres humanos e um agrupamento de autoridades consideradas competentes para jogarem com tais discursos; relações de poder que tornam esses processos vitais um campo aberto de disputas e negociações; e modos de subjetivação por meio dos quais os indivíduos são levados a trabalharem em si mesmos a partir desses discursos de verdade e dessas relações de poder (RABINOW; ROSE, 2006). Assim, a utilização do conceito de biopoder pode ser muito útil na compreensão das relações entre Saber, Poder e Subjetividade.

Dentro dessa perspectiva, The Politics of Life Itself... é uma tentativa de realizar um diagnóstico dos múltiplos caminhos contingentes que tem contribuído para a constituição do campo de problematizações biopolíticas contemporâneas. 0 principal argumento de Rose é que possivelmente está se constituindo uma forma emergente de vida, na qual nos tornamos seres que compreendem a si mesmos a partir de sua constituição biológica e corporal, e que tal constituição é entendida como aberta a um trabalho de intervenção, possível de ser manipulada como um projeto. Dentro dessa forma emergente, Rose sugere que a própria vida se tornou um campo aberto de contestação e disputa política, o que ele denomina de política vital, ou de política da própria vida (vital politics ou politics of life itself), na qual novas articulações entre saber, poder e subjetividade se manifestam.

Rose é insistente em apontar que algo novo está acontecendo, resultado de um conjunto de diversos processos que confluem no presente, que potencialmente podem gerar diversos futuros. A fim de realizar uma forma específica de genealogia, denominada por ele de "história dos futuros possíveis", Rose organiza o que considera ser as principais mutações biopolíticas contemporâneas em cinco caminhos: a molecularização, a optimização, a subjetificação, a constituição de 
uma perícia somática e a organização e expansão de uma economia da vitalidade ou bioeconomia.

Amolecularização diz respeito às mutações que vêm ocorrendo na área dos saberes biomédicos a partir das quais os processos vitais estão sendo compreendidos nos seus aspectos constitutivos mais elementares, no nível molecular. Constitui-se, assim, um estilo de pensamento no qual a vida se apresenta como resultado da interação dessas partículas moleculares, que podem ser identificadas, isoladas, manipuladas e recombinadas em novas práticas de intervenção que não mais são constrangidas pela aparente normatividade da ordem natural.

A optimização é o caminho pelo qual as tecnologias contemporâneas da vida deixaram de ser limitadas pelos pólos da saúde/doença. Apesar de tais pólos permanecerem, sua relação se tornou mais fluida e aberta à intervenção, como pode ser observado nas linguagens da susceptibilidade e do aprimoramento, que reorganizam as idéias de risco, predisposição, constituição genética, etc., e tornam possível a intervenção no presente visando futuros planejados.

Subjetificação é o processo no qual os indivíduos são cada vez mais convocados a tomarem uma posição ativa com relação a suas vidas, no sentido de se engajarem num trabalho sobre si. Esse trabalho sobre si se organiza a partir da constituição de um valor ético em torno da vida, na qual esses indivíduos compreendem a si mesmos como seres dotados de uma constituição biológica e corporal aberta à intervenção, e, logo, à responsabilidade. Desenvolve-se, então, uma ética e uma política somáticas, assim como surgem diversas práticas de subjetificação em torno da ação, individual e/ou coletiva, sobre o vital, que Rabinow (1996) denominou de biossocialidade e que Rose denomina de cidadania biológica.

Para o autor, nessa rede constituída pelos processos de molecularização, optimização e subjetificação há, por um lado, a proliferação de um rol de novas autoridades consideradas competentes a serem os portadores das verdades sobre a vida e a aconselharem os indivíduos nas suas buscas por uma vida com mais qualidade. Esses "experts do soma" compreendem diversas profissões que ocupam os mais diversos espaços, desde o laboratório e a clínica até a vida cotidiana. Por outro lado, tal campo abre possibilidades novas de capitalização em torno da vida, na qual se torna possível o desenvolvimento de algo como o biocapital, e a expansão de uma bioeconomia, em que essas entidades moleculares adquirem valor econômico, e a própria produção da verdade biológica se torna cada vez 
mais dependente da rede de investimentos, como se pode observar na atual interdependência entre o saber biomédico e a indústria farmacêutica.

Em The Politics of Life Itself Rose analisa esses cinco caminhos de mutação e apresenta um vasto material empírico para ilustrar seus argumentos a fim de realizar o que ele chama de uma cartografia preliminar do presente e a história dos futuros possíveis. Seu objetivo, com isso, é a tentativa de compreensão do nosso momento, de maneira a instrumentalizar nossa capacidade de ação crítica e de intervenção nesse presente, a fim de que possamos perceber quais futuros possíveis nos aguardam.

0 livro traz importantes contribuições para aqueles que se interessam na perspectiva biopolítica e na compreensão das conseqüências desses novos rearranjos entre saber, poder e subjetividade. Entretanto, há que se tomar o cuidado de não exagerar o elemento da novidade e tomar uma posição que afirme que estamos vivendo um momento único na história. 0 próprio Rose cai nesse erro, já que, apesar de comentar sobre a importância em reconhecermos as continuidades, ele mesmo acaba por se surpreender e em diversos momentos do texto apresenta as questões de uma forma um tanto quanto profética.

Outro elemento do livro que considero problemático é a insistência de Rose na criação de novos termos. Se, por um lado, as especificidades dos problemas contemporâneos demandam análises próprias, temos também que há continuidades entre as questões atuais e as antecessoras. Assim, a criação indiscriminada de diversos termos e conceitos novos acaba por ser um processo analítico muito dispendioso e confuso. Nesse sentido, é muito mais interessante perceber o caminho analítico que Rose percorre do que se desgastar na tentativa de absorver todos os conceitos que ele cria e recria, uma vez que os utiliza, de certa forma, de maneira indiscriminada.

\section{REFERÊNCIAS}

RABINOW, Paul. Artificiality and enlightenment: from sociobiology to biosociality. In: Press, 1996. Chap. 7. Essays on antrhopology of reason. New Jersey: Princeton University

RABINOW, Paul; ROSE, Nikolas. Introduction - Foucault today. In: The essential Foucault: selections from the essential works of Foucault, 1954-1984. New York: New Press, 2003. p.vii-xxxv. 
Biopower today. BioSocieties, v. 1, p. 195-217, 2006.

R0SE, Nikolas. Beyond medicalisation. Lancet, London, v. 369, Issue 9562, p. 700702, Feb. 2007.

Governing conduct in the age of the brain. In: Colóquio Latino-

Americano de Biopolitica, 3., 2011, Buenos Aires. Anais... Buenos Aires: UNIPE, 2011. 